\title{
Influence of Machine-Made Sand Performance on Concrete
}

\author{
Huanhuan $\mathrm{Hou}^{1 *}$ \\ ${ }^{1}$ KZJ New Materials Group Henan Co., Ltd., Xinxiang, Henan 453731, China
}

\begin{abstract}
This paper studied the influence of various performance indexes of machine-made sand on concrete work performance and admixture adaptability. The experimental results show: The MB value of machine-made sand has obvious negative effects on concrete performance and admixtures. The rockpowder content and the fineness module have relatively little influence on the working performance of concrete. The negative effect can also be reduced by adjusting the sand ratio, but the amount of external additives has a certain influence.
\end{abstract}

\section{Introduction}

With the rapid development of our country's national economy in recent years, infrastructure construction has proceeded on a large scale and gravel, the main raw material of concrete, has been consumed hugely. With the tightening of natural sand and gravel resources and increasing environmental protection, machine-made sand as an alternative resource for natural sand is also used in the production of concrete on a large scale. ${ }^{[1]}$

The preparation method of machine-made sand makes its particle shape rough and sharp, large porosity, large specific surface area, and high content of stone powder, resulting in a big difference between machinemade sand concrete and natural river sand concrete, and the changes of its performance indicators will also affect the adaptability with admixtures and concrete workability. The research results show that stone powder can improve the pore structure of concrete and enhance the compactness of the interface transition zone, thereby enhancing the performance of concrete. The increase in mud content has the most significant deterioration of concrete performance. ${ }^{[2-3]}$ Research by Song showed that as the content of flaky particles in machine-made sand increases, various performance indicators of concrete are decreasing, and the effect of flaky particles on strength is more significant in high-grade concrete. ${ }^{[4-5]}$ The good gradation of machine-made sand has the characteristics of low porosity and stable structure, which can effectively improve the volume stability of concrete and is beneficial to the strength development of hardened concrete. ${ }^{[6-7]}$

In the actual production process, it is difficult to change the performance characteristics of machine-made sand again. It is mainly to adjust the state of concrete in combination with the mix ratio and admixtures, and there are relatively few studies in this area. This paper mainly studies the influence of various performance indexes of machine-made sand on the adaptability of polycarboxylic acid and the work performance of concrete, which provides a theoretical basis for the control in actual production.

\section{Experimental}

\subsection{Raw materials}

(1) This paper uses sunstone cement, the physical properties are shown in Table 2-1:

Table 2-1 The physical properties of the cement used in the experiment

\begin{tabular}{|c|c|c|c|}
\hline \multirow{2}{*}{$\begin{array}{c}\text { Cement } \\
\text { Varieties }\end{array}$} & \multirow{2}{*}{$\begin{array}{c}\text { Standard Water } \\
\text { Consumption } / \%\end{array}$} & \multicolumn{2}{|c|}{ Setting Time /min } \\
\cline { 3 - 4 } & 27.0 & Initial Setting & Final Set \\
\hline PO42.5 & 201 & 256 \\
\hline \multicolumn{2}{|c|}{ Flexural Strength $/ \mathrm{MPa}$} & \multicolumn{2}{|c|}{ Compressive Strength /MPa } \\
\hline $3 \mathrm{~d}$ & $28 \mathrm{~d}$ & $3 \mathrm{~d}$ & $28 \mathrm{~d}$ \\
\hline 5.5 & 9.1 & 27.8 & 50.8 \\
\hline
\end{tabular}

(2) Polycarboxylic acid admixture: meet the standard GB 8076-2008 "Concrete admixtures", self-made.

(3) The stones and test indicators used in the experiment are shown in the following table:

Table 2-2 Stones and indicators used in the experiment

\begin{tabular}{|c|c|c|c|c|}
\hline $\begin{array}{c}\text { Apparent } \\
\text { Density } \\
/\left(\mathrm{kg} / \mathrm{m}^{3}\right)\end{array}$ & $\begin{array}{c}\text { Bulk } \\
\text { Density / } \\
\left(\mathrm{kg} / \mathrm{m}^{3}\right)\end{array}$ & $\begin{array}{c}\text { Mud } \\
\text { Content } \\
/ \%\end{array}$ & $\begin{array}{c}\text { Crush } \\
\text { Value }\end{array}$ & $\begin{array}{c}\text { Needle } \\
\text { Flake } \\
\text { Content } \\
/ \%\end{array}$ \\
\hline 2740 & 1540 & 0.3 & 7.4 & 1 \\
\hline
\end{tabular}

(4) The super fine sand used in the experiment and the test indicators are shown in the following table:

Table 2-3 Superfine sand index for experiment

\begin{tabular}{cccc}
\hline $\begin{array}{c}\text { Bulk Density / } \\
\left(\mathrm{kg} / \mathrm{m}^{3}\right)\end{array}$ & $\begin{array}{c}\text { Void } \\
\text { Ratio } / \%\end{array}$ & $\begin{array}{c}\text { Fineness } \\
\text { Modulus }\end{array}$ & $\begin{array}{c}\text { Mud } \\
\text { Content } / \%\end{array}$ \\
\hline 1370 & 48 & 0.6 & 1.00 \\
\hline
\end{tabular}


(5) The machine-made sand used in the experiment and its basic characteristics and mineral composition are shown in Tables 2-4 and 2-5:

Table 2-4 Basic characteristics of machine-made sand

\begin{tabular}{|c|c|c|c|c|}
\hline $\begin{array}{c}\text { Sample } \\
\text { Code }\end{array}$ & MB & $\begin{array}{c}\text { Fineness } \\
\text { Modulus }\end{array}$ & $\begin{array}{c}\text { Stone } \\
\text { Powder } \\
\text { Content/\% }\end{array}$ & $\begin{array}{c}\text { Crush } \\
\text { Value }\end{array}$ \\
\hline S-1 & 1 & 3.3 & 5.53 & 16.42 \\
\hline S-2 & 0.75 & 3.51 & 5.04 & 13.74 \\
\hline S-3 & 1 & 2.86 & 5.59 & 11.07 \\
\hline S-4 & 0.5 & 3.14 & 5.24 & 9.58 \\
\hline S-5 & 1.5 & 3.22 & 6.8 & 18.95 \\
\hline S-6 & 1.75 & 3.29 & 6.54 & 19.28 \\
\hline S-7 & 0.75 & 3.1 & 7.16 & 13.21 \\
\hline S-8 & 0.75 & 3.12 & 12.06 & 19.53 \\
\hline S-9 & 0.75 & 3.46 & 10.51 & 11.21 \\
\hline
\end{tabular}

Table 2-5 Mineral composition analysis of machine-made sand

\begin{tabular}{|c|c|c|c|c|c|c|}
\hline & S-1 & S-5 & S-6 & S-7 & S-8 & S-9 \\
\hline $\mathrm{SiO}_{2}$ & 6.65 & 11.11 & 18.03 & 6.57 & 11.49 & 3.97 \\
\hline $\mathrm{Fe}_{2} \mathrm{O}_{3}$ & 0.83 & 1.44 & 1.05 & 0.87 & 1.32 & 0.51 \\
\hline $\mathrm{Al}_{2} \mathrm{O}_{3}$ & 0.98 & 2.76 & 1.94 & 1.4 & 2.68 & 0.86 \\
\hline $\mathrm{CaO}$ & 48.89 & 42.1 & 41.8 & 42.23 & 43.51 & 51.4 \\
\hline $\mathrm{MgO}$ & 4.37 & 3.78 & 6.92 & 7.7 & 3.7 & 2.96 \\
\hline Else & 38.28 & 38.81 & 30.26 & 41.23 & 37.3 & 40.3 \\
\hline
\end{tabular}

It can be seen from Table 2-4 that there is no obvious linear relationship between the MB value of machinemade sand and the stone powder content.

It can be seen from Table 2-5 that the selected machine-made sand has high calcium oxide content, all exceeding $40 \%$, and the highest content is $51.43 \%$. The silica content is the second, indicating that the machinemade sand is a calcium oxide rock.

\subsection{Performance test method}

The performance of concrete is implemented in accordance with GB 8076-2008 "Concrete Admixtures", and related performance indicators are tested.

\section{Experimental results and discussion}

\subsection{The effect of MB value on concrete}

Select machine-made sand with different $M B$ values to determine the effect of machine-made sand $\mathrm{MB}$ value on the amount of water-reducing agent, concrete loss over time and strength changes. The test results are shown in Table 3-1, and the strength development trend is shown in Figure 3-1:
Table 3-1 Concrete performance test

\begin{tabular}{|c|c|c|c|c|c|}
\hline \multirow{2}{*}{$\begin{array}{c}\text { Sample } \\
\text { Code }\end{array}$} & \multirow{2}{*}{$\begin{array}{c}\text { Dosage } \\
/ \%\end{array}$} & \multicolumn{2}{|c|}{ Slump $/ \mathrm{mm}$} & \multicolumn{2}{c|}{$\begin{array}{c}\text { Expansion } \\
/ \mathrm{mm}\end{array}$} \\
\cline { 3 - 6 } & & $0 \mathrm{~h}$ & $1 \mathrm{~h}$ & $0 \mathrm{~h}$ & $1 \mathrm{~h}$ \\
\hline S-4 & 1.8 & 220 & 220 & 580 & 540 \\
\hline S-1 & 1.8 & 220 & 210 & 560 & 530 \\
\hline S-5 & 2.0 & 220 & 200 & 580 & 520 \\
\hline S-6 & 2.2 & 230 & 190 & 590 & 480 \\
\hline
\end{tabular}

From the analysis in Table 3-1, it can be seen that with the increase of MB value, the admixture content increases significantly, and its loss over time also increases significantly. This is because the adsorption performance of the machine-made sand, which is reflected by the $\mathrm{MB}$ value, will reduce the effective content of the admixture in the concrete, resulting in an increase in the admixture content and increasing the concrete loss over time.

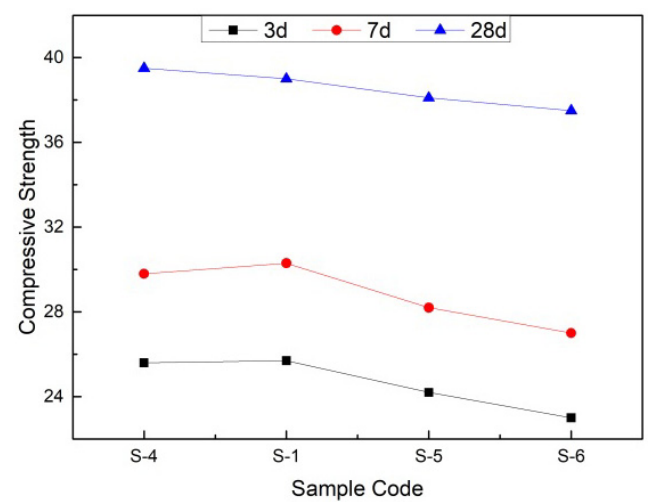

Fig. 3-1 Influence of MB value on strength

It can be seen from Figure 3-1 that the strength of concrete has a certain effect when the MB value is lower than 1.4 but is not obvious, and it will be significantly reduced when the $\mathrm{MB}$ value is above 1.4 , indicating that the impact on the strength of concrete is not significant when the MB value is lower, and the strength will be significantly reduced when the MB value exceeds 1.4.

Choose different machine-made sand with different MB value, change the sand ratio of concrete mix, compare and analyze the data change and strength change of different machine-made sand $\mathrm{MB}$ value change sand ratio and water-reducing agent dosage and concrete loss over time. The test results are shown in Table 3-2:

Table 3-2 Concrete performance test

\begin{tabular}{|c|c|c|c|c|c|c|}
\hline \multirow{2}{*}{$\begin{array}{c}\text { Sample } \\
\text { Code }\end{array}$} & $\begin{array}{c}\text { Sand } \\
\text { Rate } \\
\end{array}$ & \multirow{2}{*}{$\begin{array}{c}\text { Dosage } \\
/ \%\end{array}$} & \multicolumn{2}{|c|}{$\begin{array}{c}\text { Slump } \\
/ \mathrm{mm}\end{array}$} & \multicolumn{2}{|c|}{$\begin{array}{c}\text { Expansion } \\
\text { /mm }\end{array}$} \\
\hline S-4 & 47 & 1.8 & 220 & $1 \mathrm{~h}$ & $0 \mathrm{~h}$ & $1 \mathrm{~h}$ \\
\hline S-4 & 49 & 1.8 & 220 & 210 & 590 & 540 \\
\hline S-1 & 47 & 1.8 & 225 & 210 & 570 & 500 \\
\hline S-1 & 49 & 1.9 & 220 & 210 & 580 & 500 \\
\hline
\end{tabular}




\begin{tabular}{|l|l|l|l|l|l|l|}
\hline S-6 & 47 & 2.2 & 230 & 210 & 600 & 510 \\
\hline S-6 & 49 & 2.5 & 230 & 190 & 590 & 460 \\
\hline
\end{tabular}

Analysis of the above table shows that as the MB value increases, the impact of increasing the sand rate on the concrete becomes more and more obvious, especially when the MB value $>1.4$. This is because when the MB value is small, the machine-made sand mainly contains stone powder, and the main factor affecting the admixture is that the specific surface area is larger and the water absorption is higher. At this time, increasing the sand rate has less effect on the admixture content and the concrete loss over time; When MB>1.4, the machinemade sand mainly contains mud, and the adsorption of the admixture is more serious, which will significantly reduce the effective content of the admixture. At this time, increasing the sand rate and the amount of the admixture and the loss of concrete over time are more significant.

\subsection{Influence of stone powder content on concrete}

Select machine-made sand with different stone powder content, adjust the concrete sand ratio to make the initial state of concrete similar, and determine the influence of machine-made sand powder content on the amount of water reducing agent, concrete loss over time and strength change. The test results are shown in Table 3-3, and the strength development trend is shown in Fig. 3-2:

Table 3-3 Concrete performance test

\begin{tabular}{|c|c|c|c|c|c|c|}
\hline \multirow{2}{*}{$\begin{array}{c}\text { Sample } \\
\text { Code }\end{array}$} & $\begin{array}{c}\text { Sand } \\
\text { Rate } \\
/ \%\end{array}$ & \multirow{2}{*}{$\begin{array}{c}\text { Dosage } \\
/ \%\end{array}$} & \multicolumn{2}{|c|}{ Slump $/ \mathrm{mm}$} & \multicolumn{2}{|c|}{$\begin{array}{c}\text { Expansion } \\
/ \mathrm{mm}\end{array}$} \\
\cline { 4 - 7 } & & $0 \mathrm{~h}$ & $1 \mathrm{~h}$ & $0 \mathrm{~h}$ & $1 \mathrm{~h}$ \\
\hline S-7 & 47 & 1.8 & 230 & 220 & 590 & 540 \\
\hline S-8 & 47 & 1.9 & 220 & 210 & 580 & 520 \\
\hline S-2 & 49 & 1.8 & 220 & 210 & 570 & 520 \\
\hline S-9 & 49 & 1.9 & 225 & 220 & 580 & 520 \\
\hline
\end{tabular}

With reference to the comparative analysis of the experimental results in the above table, it can be seen that the admixture content increases with the increase of the powder content. This is because the higher the stone powder content, the larger the specific surface area of machine-made sand, which requires a higher water reducing rate, and the amount of water reducing agent used increases. When the content of stone powder increases, the flow rate of concrete slows down, which is caused by excessive slurry in the system.

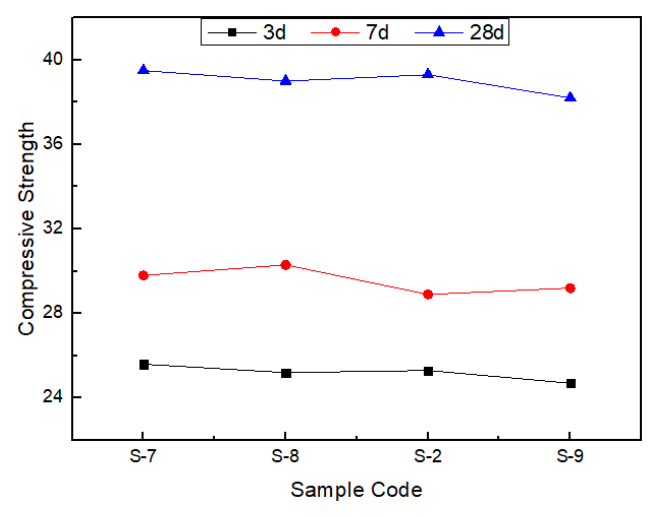

Fig. 3-2 Influence of stone powder content on strength

It can be seen from Figure 3-2 that the mechanism is that when the content of stone powder is less than $10 \%$, the strength of concrete changes little, but when the content is higher than $10 \%$, the strength of concrete decreases. This is because the right amount of stone powder has the effect of improving the gradation and filling the pores, but the stone powder does not participate in the hydration reaction of concrete, and too high content will affect its overall response and reduce its strength.

\subsection{Influence of fineness modulus on concrete}

Select machine-made sand with different fineness modulus, adjust the concrete sand ratio to make the initial state of concrete similar, determine the influence of machine-made sand fineness modulus on the amount of water reducing agent and the loss and strength of concrete over time. The test results are shown in Table $3-3$, and the strength development trend is shown in Figure 3-3:

Table 3-4 Concrete performance test

\begin{tabular}{|c|c|c|c|c|c|c|}
\hline \multirow{2}{*}{$\begin{array}{c}\text { Sample } \\
\text { Code }\end{array}$} & \multirow{2}{*}{$\begin{array}{c}\text { Sand } \\
\text { Rate } / \%\end{array}$} & \multirow{2}{*}{$\begin{array}{c}\text { Dosage } \\
/ \%\end{array}$} & \multicolumn{2}{|c|}{$\begin{array}{c}\text { Slump } \\
/ \mathrm{mm}\end{array}$} & \multicolumn{2}{|c|}{$\begin{array}{c}\text { Expansion } \\
/ \mathrm{mm}\end{array}$} \\
\cline { 4 - 8 } & & $0 \mathrm{~h}$ & $1 \mathrm{~h}$ & $0 \mathrm{~h}$ & $1 \mathrm{~h}$ \\
\hline S-3 & 47 & 1.8 & 230 & 210 & 570 & 520 \\
\hline S-4 & 47 & 1.8 & 220 & 210 & 580 & 540 \\
\hline S-1 & 47 & 1.8 & 230 & 220 & 590 & 540 \\
\hline S-2 & 47 & 1.8 & 210 & - & 580 & - \\
\hline S-2 & 49 & 1.9 & 230 & 220 & 590 & 550 \\
\hline
\end{tabular}

The analysis of the above table shows that with the same sand rate, as the fineness modulus becomes larger, the overall and workability of the concrete becomes worse. This is because when the fineness modulus increases, the fine particles of concrete decrease, the gradation becomes worse, the amount of slurry in the concrete decreases, and the encapsulation of aggregates decreases. As the fineness modulus increases, the concrete state becomes worse. After increasing the sand rate to achieve a similar degree of expansion, the demand for external additives is greater, and the loss is more significant. This is because the increase in sand 
ratio leads to an increase in the content of stone powder in the concrete, an increase in the specific surface area, a higher water reduction rate is required, and the increase in the amount of cement in the concrete system that has a strong adsorption effect on the admixture makes the loss of concrete more obvious

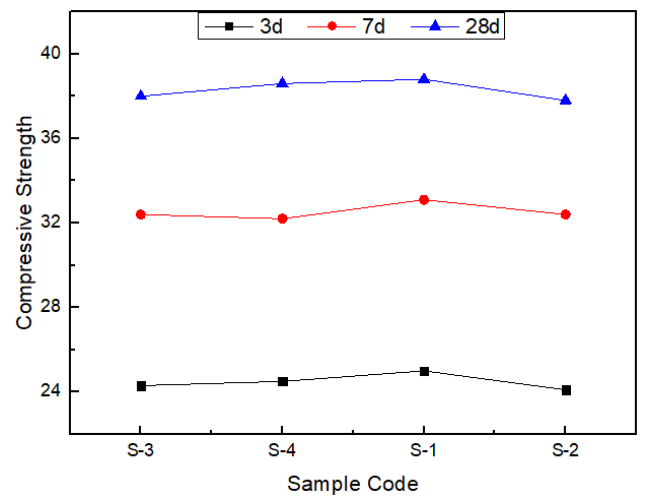

Fig. 3-3 Influence of fineness modulus on strength

Combined with the analysis of Figure 3-3, it can be seen that by adjusting the sand ratio to improve the influence of the fineness modulus of the machine-made sand, the final concrete strength development changes less. This is because the fineness modulus mainly affects the concrete gradation. After adjusting the sand ratio, this effect is basically eliminated, and the final concrete working performance is affected less.

Based on the above experimental results and the analysis in Table 2-5, it can be seen that the machinemade sand is a rock made of calcium oxide. Although its calcium oxide and other components are obviously different, it has no obvious correlation with the concrete state, admixture content and strength development as a whole.

\section{Conclusion}

1)The MB value of machine-made sand has a greater impact on the state, strength and admixture content of concrete, especially when the MB value exceeds the national standard, the negative impact on concrete is more serious;

2) The stone powder content of machine-made sand has relatively little effect on the state and strength development of concrete. It can be adjusted by changing the sand ratio to reduce the negative effect, but it will affect the admixture content;

3) The fineness modulus of machine-made sand has a great influence on the state of concrete. It is necessary to significantly change the sand ratio to offset its negative effect, which will eventually affect the amount of admixtures, and the strength is relatively small. Captions should be typed in 9-point Times. They should be centred above the tables and flush left beneath the figures.

\section{References}

1. $\mathrm{H} \mathrm{Lu}, \mathrm{G} \mathrm{H}$ Li.. Research status and existing problems analysis of machine-made sand concrete [J]. Sichuan Building Materials. 40,1:3 6, (2014),.

2. C J Liu, Z H Wu. Experimental Study tuff sand polycarboxylic acid adaptability [J]. Journal of Ningbo University of Technology, 27,1 :1 5 (2015).

3. F Y X Guo, J X Gong. Influence of stone powder content on the mechanical properties and durability of concrete.[J] Journal of Building Materials, 12,3:266 271(2009).

4. S M Song, D Guo. Influence of the content of flake particles of machine-made sand on the performance of cement mortar and concrete.[J] Concrete, 12:60 62,(2015).

5. S M Zhao. Influence of machine-made sand quality on concrete performance.[D] Social Sciences Edition,2016.

6. J Huang, Y Lv, L Zhang. Research on performance of artificial sand with different fineness modulus applied to concrete. [J] CC,05(2015).

7. Wallevik.O.H, Wallevik.J.E. Rheology as a tool in concrete science: The use of rheographs and workability boxes. [J]CCR,41,12(2011). 